\title{
Studies on Growth and Flowering Behavior of Newly Evolved Genotypes of Chrysanthemum (Dendranthema grandiflora Tzvelev) for Loose Flower Production
}

\author{
Reshma Negi", S.R. Dhiman and Y.C. Gupta
}

Department of Floriculture and Landscape Architecture, College of Horticulture, Dr. Yashwant Singh Parmar University of Horticulture and Forestry, Nauni - Solan (Himachal Pradesh) India - 173230

*Corresponding author

\section{A B S T R A C T}

\begin{tabular}{|l|}
\hline Ke y w o r d s \\
Chrysanthemum, \\
Genotypes, \\
Flowering, \\
Production \\
Technology, \\
Germplasm
\end{tabular}

\section{Introduction}

Chrysanthemum (Dendranthema grandiflora Tzvelev) belongs to family Asteraceae (Andreson, 1987) and native to Northern hemisphere chiefly Europe and Asia. It is the national flower of Japan and commonly called
An experiment was conducted to study the growth and flowering behavior of newly evolved nineteen genotypes of chrysanthemum (Dendranthema grandiflora Tzvelev) including cultivar 'Surf' as standard check for loose flower production at the Experimental Farm of Department of Floriculture and Landscape Architecture, Dr. Yashwant Singh Parmar University of Horticulture and Forestry, Nauni, Solan, Himachal Pradesh during the year 2016-17. Among different genotypes, maximum plant height was recorded in genotype 'UHFSChr128' $(120.33 \mathrm{~cm})$. The number of stems per plant were observed maximum in 'UHFSChr 131' (6.67) followed by 'UHFSChr'118' (6.33). The cultivar 'Surf' took minimum number of days for visible flower bud formation (76.07 days) followed by genotypes 'UHFSChr 111' (95.80 days), 'UHFSChr 123' (96.33 days) and 'UHFSChr 115' (96.93 days). In contrast, genotype 'UHFSChr129' took maximum number of days for visible flower bud formation (123 days). Significantly lesser number of days taken for flowering was recorded in cultivar 'Surf' (109.13 days) whereas, genotype 'UHFSChr129' (154 days) took maximum days for flowering. Maximum number of flowers per plant were observed in cultivar 'UHFSChr128' (474.93) followed by 'UHFSChr132' (435.93) and 'UHFSChr117' (408.33) where as minimum number of flowers were observed in genotype 'UHFSChr124' (29.59). The duration of flowering was found maximum in genotype 'UHFSChr111' (34.00 days). 
growth habit, size and shape. It is used for cut flower and loose flower as well as making garlands, venis, gajras and religious offering.

The extra large-bloomed cultivars are prized for their exhibition value. The utility and popularity of chrysanthemum have increased immensely with the introduction of the techniques for year round blooming based on scientific research in the field of photoperiodism and genetics.

Chrysanthemum is a short day plant and cannot normally form flower buds when the day length exceeds 14.5 hours and developed them when it exceeds 13.5 hours (Machin and Scopes, 1978). Due to nature of flowering under short-day conditions, availability of chrysanthemum flower is restricted to short span of not more than three months. As, it requires long days for vegetative growth and short days for flowering. It is grown under wide range of climatic conditions but the performance of the genotype varies with the region, season and other growing conditions. Due to of intensive research done by scientists and practical experience of many growers, its flowers can be produced throughout the year to precise schedules at any time by environmental manipulation, fertilization and using growth regulating chemical. However, ability to produce chrysanthemum year round depends on an understanding the complex interaction between the plant and its environment. A sound knowledge of its physiology and management practices can ensure the continued success of chrysanthemum crop despite increasing production cost.

Somehow, the available germplasm could not fulfill the requirements in terms of new colors, forms, types and various characteristics. Therefore, urgent need is felt to develop new cultivars having wide genetic adaptability and easily availability to the growers at cheapest rate, the genotypes were evolved at the deptt of Floriculture and landscape Architecture, College of Horticuture, Dr. Yashwant Singh Parmar University of Horticulture and Forestry, Nauni, Solan (Himachal Pradesh). An investigation was carried out with the objective to study the growth and flowering behavior of newly evolved genotype of chrysanthemum (Dendranthema grandiflora Tzvelev) for loose flower production.

\section{Materials and Methods}

\section{Study Area and experimental design}

The experiment was conducted at Experimental Farm of Department of Floriculture and Landscape Architecture, College of Horticulture, Dr. Yashwant Singh Parmar University of Horticulture and Forestry, Nauni- Solan (Himachal Pradesh), India during 2016-17.

Uniform healthy rooted plants were planted at a spacing of $30 \times 30 \mathrm{~cm}$ in randomized block design with three replications consisting nine plants in each replication under open field conditions. Using FYM and NPK @ $5 \mathrm{~kg} / \mathrm{m}^{2}$ and $22.5 \mathrm{~g}$ P (Single Super Phosphate-140.62 $\mathrm{g} / \mathrm{m}^{2}$ ) and $\mathrm{K}$ (Muriate of Potash-37.5 $\mathrm{g} / \mathrm{m}^{2}$ ) and $11.25 \mathrm{~g}$ of $\mathrm{N}$ (Urea-24.46g $/ \mathrm{m}^{2}$ ) should be applied after 30 days of planting respectively. Five plants were selected from each replication for getting observation. The observations were recorded after bud initiation stage and uniform package and practices were followed throughout the cropping season. Data were recorded for both vegetative and flowering attributes like number of flower per plant, days taken for bud initiation, days taken to flowering, flowering duration (days), plant height $(\mathrm{cm})$, plant spread $\left(\mathrm{cm}^{2}\right)$, flower diameter $(\mathrm{cm})$ and flower weight $\left(\mathrm{kg} / \mathrm{m}^{2}\right)$, using the standard method. The collected data were analysed statistically as per standard methods of Gomez and Gomez (1984). 


\section{Genotypes used}

In total, following nineteen newly evolved genotypes were used in the present investigation in order to assess their growth and flowering along with 'Surf' (standard check) under open field conditions:

\section{Results and Discussion}

Among different genotypes, maximum plant height was recorded in genotype 'UHFSChr128' $(120.33 \mathrm{~cm})$ whereas minimum in cultivar 'Surf' $(39.27 \mathrm{~cm})$ as depicted in Table 1. The variation in plant height of different cultivars of chrysanthemum has also been reported by Barigidad and Patil (1997), Laxmi et al., (2008), Sawaroop et al., (2008), Palai (2009), Banerji et al., (2012) and Kumar et al., (2012) and Punetha et al., (2011).

The number of stems per plant were observed maximum in 'UHFSChr125' and 'UHFSChr125' (6.67) in contrast, minimum number of stems were noted in genotype 'Surf' (4.37). The number of stem varied with the genotypes which resulted best after pinching. Swaroop et al., (2008) evaluated different genotypes of chrysanthemum recorded maximum number of branches per plant. The cultivar 'Surf' took minimum number of days for visible flower bud formation (76.07 days). In contrast, genotype 'UHFSChr129' took maximum number of days for visible flower bud formation (123 days). Significantly lesser number of days taken for flowering by genotype 'Surf' (109.13 days) whereas, 'UHFSChr129' (154 days) took maximum days for flowering. In similar study Negi et al., (2015) also reported the variation for days taken to flowering different cultivars of chrysanthemum. The largest flowers were found in genotype
'UHFSChr124' (10.17cm). In contrast, smallest sized flowers were observed in 'UHFSChr128' (3.07cm).

The variation in flower size in the genotypes may be attributed due to inherent genetic characters of the individual cultivars and environmental factors reported by Biradur and Khan (1996); Singh and Ramchandran (2002). The increase in flower size may be due to disbudding also. It was however, found to be statistically at par with genotype 'UHFSChr118' $(3.3 \mathrm{~cm})$. The perusal of data from Table 2 envisages that maximum numbers of flowers per plant were observed in genotype 'UHFSChr128' (447.49) followed by 'UHFSChr132' (435.93) and 'UHFSChr117' (408.33). On the other hand, minimum numbers of flowers were observed in genotype 'UHFSChr124' (29.59). The number of flowers per plant determines the better growth and flower yield of chrysanthemum. Poonam and Ashok Kumar (2007) and Kumar et al., (2015) reported that vegetative growth significantly contribute towards the flower yield of chrysanthemum. Variation in number of flowers was observed by Yadav et al., (2014).

Maximum flower yield per meter square was observed in genotype 'Surf' $\left(6316.8 \mathrm{gm} / \mathrm{m}^{2}\right)$, 'UHFSChr132' $\left(6192.00 / \mathrm{m}^{2}\right)$ and minimum was in genotype 'UHFSChr124' $\left(1253.52 / \mathrm{m}^{2}\right)$. The difference in yield may be due to the additive gene effect (Behera et al., (2002). The increase in yield may be due to the increased flower size, flower weight and number of branches per plant (Suvija et al., 2016). The duration of flowering was found maximum in genotype 'UHFSChr111' (34.00 days). Variation among different cultivars for duration of flowering was also been observed by Talukdar et al., (2006), Kumar et al., (2014). 
Table.1

\begin{tabular}{|c|c|c|c|}
\hline Sr. no. & Genotype & Sr. no. & Genotype \\
\hline $\mathbf{1}$ & UHFSChr111 & 10 & UHFSChr123 \\
\hline $\mathbf{2}$ & UHFSChr113 & 11 & UHFSChr124 \\
\hline $\mathbf{3}$ & UHFSChr114 & 12 & UHFSChr125 \\
\hline $\mathbf{4}$ & UHFSChr115 & 13 & UHFSChr126 \\
\hline $\mathbf{5}$ & UHFSChr117 & 14 & UHFSChr128 \\
\hline $\mathbf{6}$ & UHFSChr118 & 15 & UHFSChr129 \\
\hline $\mathbf{7}$ & UHFSChr120 & 16 & UHFSChr130 \\
\hline $\mathbf{8}$ & UHFSChr121 & 17 & UHFSChr131 \\
\hline $\mathbf{9}$ & UHFSChr122 & 18 & UHFSChr132 \\
\hline $\mathbf{1 9}$ & \multicolumn{4}{|c}{ Surf (Standard check) } \\
\hline
\end{tabular}

Table.2 Variation in different growth and flowering parameters of newly evolved genotypes of Chrysanthemum under Nauni (Solan) conditions during 2016-17 for loose flower production

\begin{tabular}{|c|c|c|c|c|c|c|c|c|c|c|c|}
\hline $\begin{array}{l}\text { Sr } \\
\text { No }\end{array}$ & Genotypes & $\begin{array}{c}\begin{array}{c}\text { Bud } \\
\text { formation } \\
\text { (Days) }\end{array} \\
\end{array}$ & $\begin{array}{c}\text { Days taken } \\
\text { to } \\
\text { flowering }\end{array}$ & $\begin{array}{c}\text { Plant } \\
\text { height } \\
(\mathbf{c m})\end{array}$ & $\begin{array}{c}\text { Number of } \\
\text { Stems } \\
\text { /Plant }\end{array}$ & $\begin{array}{r}\text { Plant } \\
\text { spread } \\
\text { (cm) }\end{array}$ & $\begin{array}{c}\text { Flower } \\
\text { size } \\
(\mathrm{cm})\end{array}$ & $\begin{array}{l}\text { Duration of } \\
\text { flowering } \\
\text { (days) }\end{array}$ & $\begin{array}{c}\text { Number of } \\
\text { flower/Plant }\end{array}$ & $\begin{array}{c}\text { No of flower } \\
\text { (gm)/Plant }\end{array}$ & $\begin{array}{l}\text { Weight of } \\
\text { flower } \\
\mathrm{g} / \mathrm{m}^{2}\end{array}$ \\
\hline 1 & UHFSChr111 & 95.80 & 137.33 & 62.66 & 4.67 & 40.00 & 5.47 & 34.00 & 235.33 & 494.20 & 4447.80 \\
\hline 2 & UHFSChr113 & 101.00 & 138.73 & 91.60 & 5.33 & 37.67 & 5.40 & 27.67 & 225.33 & 450.67 & 4056.00 \\
\hline 3 & UHFSChr114 & 97.00 & 137.67 & 113.33 & 5.67 & 36.33 & 4.83 & 27.00 & 284.67 & 341.60 & 3074.40 \\
\hline 4 & UHFSChr115 & 96.93 & 139.87 & 113.40 & 6.33 & 41.00 & 6.33 & 27.33 & 199.33 & 418.60 & 3767.40 \\
\hline 5 & UHFSChr117 & 98.60 & 135.33 & 101.00 & 6.00 & 39.67 & 3.84 & 28.00 & 402.67 & 644.27 & 5798.13 \\
\hline 6 & UHFSChr118 & 99.20 & 138.40 & 76.73 & 5.67 & 32.00 & 3.30 & 27.33 & 147.33 & 139.28 & 1253.52 \\
\hline 7 & UHFSChr120 & 99.40 & 138.33 & 69.73 & 5.67 & 36.00 & 5.50 & 33.00 & 191.00 & 204.35 & 1839.18 \\
\hline 8 & UHFSChr121 & 97.93 & 130.87 & 97.00 & 5.33 & 38.00 & 4.50 & 27.00 & 235.67 & 348.77 & 3138.90 \\
\hline 9 & $\mathrm{UHF}^{\prime}$ & 97.40 & 130.27 & 78.00 & 6.67 & 36.00 & 5.33 & 27.67 & 346.67 & 627.46 & 5647.11 \\
\hline 10 & UHFSChr123 & 96.33 & 128.60 & 82.33 & 4.67 & 37.00 & 5.77 & 27.33 & 58.33 & 169.17 & 1522.50 \\
\hline 11 & UHFSChr124 & 98.00 & 138.67 & 72.00 & 4.67 & 26.67 & 10.33 & 30.33 & 30.33 & 221.43 & 1992.90 \\
\hline 12 & UHFSChr125 & 99.53 & 139.93 & 105.33 & 6.67 & 38.33 & 4.50 & 27.33 & 252.67 & 235.40 & 2118.60 \\
\hline 13 & UHFSChr126 & 97.87 & 135.67 & 65.16 & 5.33 & 35.00 & 4.83 & 33.67 & 206.33 & 237.27 & 2135.40 \\
\hline 14 & UHFSChr128 & 99.20 & 136.47 & 120.33 & 6.33 & 38.33 & 2.67 & 26.33 & 448.00 & 268.80 & 2419.20 \\
\hline 15 & UHFSChr129 & 104.00 & 154.93 & 46.53 & 5.00 & 31.33 & 5.07 & 29.00 & 102.33 & 307.00 & 2763.00 \\
\hline 16 & UHFSChr130 & 101.40 & 136.00 & 89.26 & 6.67 & 34.00 & 4.57 & 32.67 & 113.00 & 169.50 & 1525.50 \\
\hline 17 & UHFSChr131 & 103.60 & 136.73 & 91.40 & 6.33 & 37.00 & 5.03 & 28.67 & 262.00 & 419.20 & 3772.80 \\
\hline 18 & UHFSChr132 & 99.27 & 139.60 & 89.60 & 6.67 & 37.33 & 5.33 & 32.33 & 430.00 & 688.00 & 6192.00 \\
\hline \multirow[t]{2}{*}{19} & Surf & 76.07 & 109.13 & 39.33 & 4.33 & 33.00 & 6.60 & 32.33 & 109.67 & 701.87 & 6316.80 \\
\hline & $C D_{0.05}$ & 2.596 & 3.205 & 8.22 & 1.220 & 4.746 & 0.643 & 3.13 & 26.536 & 44.471 & 400.295 \\
\hline
\end{tabular}


It was concluded that 'UHFSChr 132', 'UHFSChr 117', 'UHFSChr 122', 'UHFSChr 111', including 'Surf' performed comparatively better w.r.t. flower yield so these genotypes are suitable for cultivation as loose flower production.

\section{References}

Anderson RL.1987. Reclassification of genus chrysanthemum HortScience 22: 313.

Anonymous. 2017. Flora Holland https://www.royalfloraholland.com/en/ speciale-paginas/ in.../bloemenagenda2017.

Biradur MS and Khan MM.1996.performance of exotic gerbera varieties under low cost plastic greenhouse. The Lalbaugh 41:46-52.

Behera TK,PS Sirohi and Anand Pal.2002. Assessment of chrysanthemum germplasm for commercial cultivation under Delhi condition. Journal of ornamental Horticulture New series 5; 11-14.

Banerji BK, Dwivedi AK and Atul Batra 2012. Morphology and Biochemical characterization of chrysanthemum. Journal of Ornamental Horticulture 7:32-36.

Anonymous. 2019. Directorate of Horticulture. Nabahar Shimla, Himachal Pradesh.

Gomez L A and Gomez A. 1984. Statistical procedure for agriculture research. $3^{\text {rd }}$ ed. Singapore: Jhon Wiley and Sons, $p$ 680.

Kumar R Deka BC and Roy AR. 2012. Evaluation of Orchid species under sub-tropical mid hill of Meghalaya. Horticulture Flora Research Spectrum 1:49-51.

Kumar R. 2014. Evaluation of chrysanthemum genotypes for flowering traits under open grown condition. HortFlora Research Spectrum 3: 388-389.
Kumar A, Dubey P, Patanwar M and Sharma R. 2015. Evaluation of chrysanthemum for loose flower production in Chhattisgarh plains. Trends in Bioscience 8: 175-177.

Laxmi P. Pratap M and Amrender Reddy S. 2008. Evaluation of yellow coloured chrysanthemum cultivar for growth, flowering and yield. The Orissa Journal of Horticulture 36:116-119.

Machin BJ, Scopes NEA 1978. Chrysanthemum year round growing. Bladford Press, Poole-Dorset, p 233.

Matsuo E. 1990. Analysis of flower appreciation and its international comparison contribute to progress of flower production and international flower trade. Horticultural Science 25:1468-1471.

Negi R, Jarial K, Kumar S and Dhiman SR. 2015. Evaluation of different cultivars of chrysanthemum suitable for low hill conditions of Himachal Pradesh. Journal of Hill Agriculture 6: 144-146.

Punetha P, Rao VK and Sharma SK. 2011. Evaluation of different chrysanthemum genotype under mid hill conditions of Garhwal Himalaya. The Indian Journal of Agriculture Sciences 9:830833.

Poonam and Kumar A. 2007. Garden BeautyA promising chrysanthemum cultivar for garden decoration. Journal of Ornamental horticulture 10:165-168.

Palai SK. 2009. Comparative studies on performance of spray chrysanthemum under open and naturally ventilated polyhouse. Journals of Ornamental Horticulture 12: 138-141.

Swaroop K, Prasad KV and Raju DVS.2008. Evaluation of chrysanthemum germplasm in winter season under Delhi conditions Journal of Ornamental horticulture 11:58-61.

Suvija NV, Suresh J, Kumar SR and Kannan M.2016. Evaluation of chrysanthemum 
(Chrysanthemum morifolium Ramat) genotypes for loose flower cut flower and pot mums. International Journals of innovative Research and Advanced Studies 3: 100-104.

Talukdar MC, Mahanta S and Sharma BJ. 2006. Evaluation of standard chrysanthemum (Dendranthema grandiflora Tzvelve) cultivars under polyhouse cum rain shelter and open field conditions. Journal of Ornamental Horticulture 9:110-113.

Yadav A, Sharma G and Dubey P. 2014. Flowering attributes of chrysanthemum varieties of loose flower production. Progressive Horticulture 46: 168-176.

\section{How to cite this article:}

Reshma Negi, S.R. Dhiman and Gupta, Y.C. 2019. Studies on Growth and Flowering Behavior of Newly Evolved Genotypes of Chrysanthemum (Dendranthema grandiflora Tzvelev) for Loose Flower Production. Int.J.Curr.Microbiol.App.Sci. 8(11): 341-346. doi: https://doi.org/10.20546/ijcmas.2019.811.043 